\title{
IMPROVING SURFACE ROUGHNESS BY ELECTRICAL DISCHARGE MACHINING WITH TUNGSTEN POWDER
}

\author{
Vantao Le ${ }^{1,2}$, Tienlong Banh ${ }^{1}$, Xuanthai Tran ${ }^{1}$, and Thi Hong Minh Nguyen ${ }^{1}$ \\ ${ }^{1}$ Hanoi University of Science and Technology, Hanoi, Vietnam, \\ Tel: +84 9828374 65, e-mail: MinhNguyenThiHong@ hust.edu.vn \\ ${ }^{2}$ Le Quy Don Technical University, Hanoi, Vietnam, Tel: +84 912505036, e-mail: taoitd@yahoo.com \\ Received Date: September 1, 2016; Revised Date: February 25, 2019; Acceptance Date: May 3, 2019
}

\begin{abstract}
Electrical discharge machining (EDM) process is widely used to process hard materials in the industry. The process of electrical discharge is changed and called PMEDM when alloy powder is added in the oil dielectric. Studies show that the surface roughness (Ra) obtained by PMEDM is generally better than that by normal EDM. In the current study, the effect of tungsten carbide alloy powder added to the dielectric on the surface roughness status of the workpiece SKD61 after machining is investigated. The experiment shows that at the selected process window, adding the powder has resulted in an improvement of the surface roughness up to $57.98 \%$ as compared to the high surface roughness Ra of $0.471 \mu \mathrm{m}$ by normal EDM.
\end{abstract}

Keywords: EDM, PMEDM, Surface roughness, Tungsten carbide powder

\section{Introduction}

EDM machining technology is widely used in mechanical manufacturing. However, its low efficiency and poor surface quality have been the key problem restricting its development. Many studies in recent years have focused on improving the quality of machining and surface quality. One of the methods to improve the quality of machining and surface quality is to mix powder into the dielectric fluid (PMEDM). In the PMEDM, the conductive particles mixed in the dielectric fluid reduces the possibility of insulating dielectric fluid and increase the electrical discharges between the electrode and the workpiece [1]. Furthermore, the spark discharges are more even and extended [2], leading to the reduced charge density which makes the craters become shallower. As a result, the process becomes more stable thereby improving machining rate and surface finish.

Erden and Bilgin [3] reported the experimental and the theoretical investigations to determine the effect of the impurities in the dielectric fluid of EDM method in 1980. They found that adding alloy powder insulation into the solvent did improve the surface quality.

Wang et al. [4] studied the impact of mixed alloy powder ( $\mathrm{Al}$ and $\mathrm{Cr}$ ) in the dielectric fluid. Wang pointed out that the technological parameters of electricity, the characteristic and the concentration of the additive in the dielectric fluid had a significant impact on technological characteristic of EDM. As a result, the metal coated and the surface roughness (SR) were changed.

Mohri et al. [5, 6, 7] studied the effects of silicon powder. The results of surface corrosion resistance and the surface roughness (Ra) of less than $2 \mu \mathrm{m}$ were produced.

Kobayashi et al. [8] investigated the effects of silicon powder in dielectric fluid on material removal rate (MRR) and SR. 
Narumiya et al. [9] proved that under specific working conditions, aluminum (Al) and graphite $(\mathrm{Gr})$ powders yielded better surface finish than the silicon $(\mathrm{Si})$ powder. The best results of Ra less than $2 \mu \mathrm{m}$ were obtained for aluminum and graphite powder.

Wong et al. [10] studied the "near-mirror-finish" phenomenon of surface in EDM using fine alloy powder such as silicon, graphite, molybdenum, aluminum and silicon carbide mixed in the dielectric fluid. Research had shown great influence of the alloy powder on the surface roughness.

Pecas and Henriques [11] investigated the influence of particles silicon (Si) mixed in the dielectric fluid. The results showed that by adding $2 \mathrm{~g} / \mathrm{l}$ of silicon ( $\mathrm{Si}$ ) powder, the processing time and the surface roughness were reduced. Average surface roughness depended on the machining area and the machining time. This surface roughness changed between $0.09-0.57 \mu \mathrm{m}$ within $1-64 \mathrm{~cm}^{2}$ area.

$\mathrm{Wu}$ et al. [12] reported the effects of surfactant and $\mathrm{Al}$ powder mixture to the surface roughness, the best surface roughness was reported of less than $2 \mu \mathrm{m}$.

Tseng and Chen [13] studied the effects of powder $\mathrm{Al}, \mathrm{Cr}, \mathrm{Cu}, \mathrm{SiC}$. It was showed that $\mathrm{Al}$ powder provided the best surface.

Yuan and Yuan [14] reported the effects of TC powder on the surface roughness. The authors concluded that the powder involved in the process of EDM provided a better surface roughness than that of conventional EDM.

Recently Jabbaripour et al. [15] studied the influence of Al powder in the process of EDM to the surface roughness of the alloy TiAl. The authors had shown that the improvement of the surface roughness compared to that of normal EDM by $32 \%$.

The above-mentioned studies however did not focus on the influence of tungsten carbide powder on the surface roughness, especially in a finishing and semi-finishing process. In this study, the authors analyze tungsten carbide powder impact on the average surface roughness at a finishing and semi-finishing process.

\section{Experiment}

The experimental flowchart is shown in Figure 1. The following sessions describe in detail the materials and methods of the experiments.

\section{Materials and Equipment}

Materials used in the experiments is from the manufacturer Daido Steel SKD61- Amistar (JIS-Japan). The chemical composition of the steel SKD61 is shown in Table 1. The dielectric fluid is Shell Oil EDM Fluid 2. The technical properties are shown in Table 2. The particle size and the chemical composition in percent by weight of tungsten carbide metal powder is shown in Table 3 and Table 4.

\section{Experimental Method}

An electrical discharge machine from the Aristech Company, model CNC-460 EDM, was used to remove the upper part of the SKD61 workpiece to obtain dimensions as in Table 5. The copper electrode polarity was negative. In this experiment, tungsten carbide metal powder was mixed into the dielectric fluid with the concentrations as in Table 5.

The parameters of the process are given in Table 5. The surface roughness was determined using a surface roughness tester TR200 - by TINE Group INC with the resolution of $0.001 \mu \mathrm{m}$. 


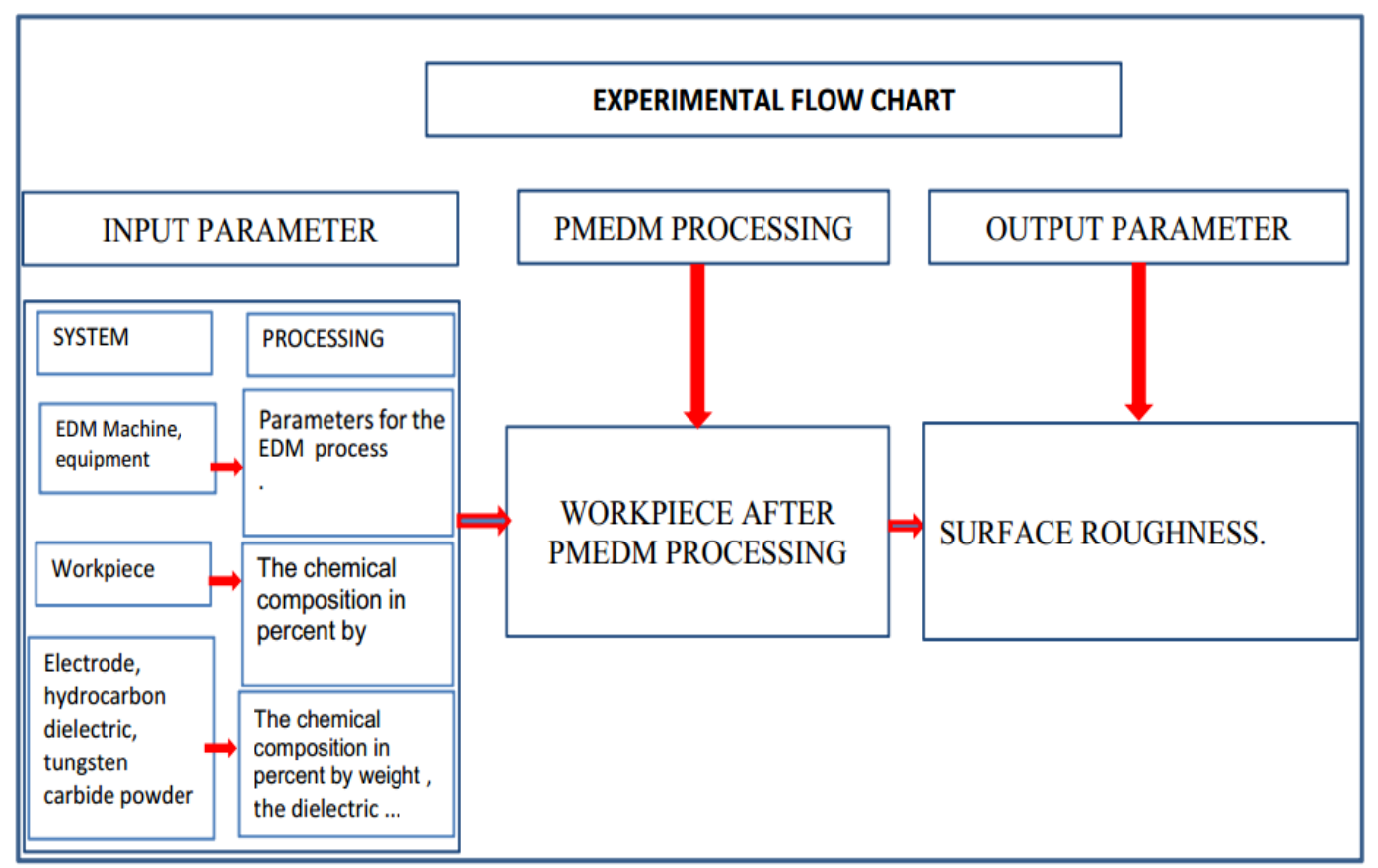

Figure 1. Experiment plan

Table 1. The Chemical Composition in Weight Percentage of SKD61

\begin{tabular}{|c|c|c|c|c|}
\hline $\mathbf{C}$ & $\mathbf{S i}$ & $\mathbf{C r}$ & Mo & V \\
\hline 0.38 & 1.0 & 5.0 & 1.25 & 1.0 \\
\hline
\end{tabular}

Table 2. The Technical Properties of Shell Oil EDM Fluid 2

\begin{tabular}{|c|c|c|}
\hline Properties & Unit & Value \\
\hline Velocity at $\mathbf{4 0}^{\mathbf{0}} \mathbf{C}$ & $\mathrm{cSt}$ & 2.25 \\
\hline Density at $\mathbf{1 5}^{\mathbf{0}} \mathbf{C}$ & $\mathrm{kg} / \mathrm{l}$ & 0.773 \\
\hline Freezing temperatures (max) & ${ }^{0} \mathrm{C}$ & -27 \\
\hline Thermal conductivity & $\mathrm{W} / \mathrm{m}^{0} \mathrm{C}$ & 0.01 \\
\hline
\end{tabular}

Table 3. The Chemical Composition of Tungsten Carbide Metal Powder

\begin{tabular}{|c|c|c|c|c|}
\hline C \% & Co \% & Fe \% & W \% & Other Components \\
\hline 5.56 & 11.9 & 0.02 & 82.5 & $<0.01$ \\
\hline
\end{tabular}

Table 4. The Particle Size in Weight Percentage of Tungsten Carbide Metal Powder

\begin{tabular}{|c|c|c|c|c|}
\hline $\mathbf{5 , 5} \boldsymbol{\mu m}$ & $\mathbf{1 1} \boldsymbol{\mu \mathbf { m }}$ & $\mathbf{1 6} \boldsymbol{\mu} \mathbf{m}$ & $\mathbf{2 2} \boldsymbol{\mu m}$ & $\mathbf{3 1} \boldsymbol{\mu m}$ \\
\hline $5.23 \%$ & $25.98 \%$ & $59.74 \%$ & $89.35 \%$ & $98.93 \%$ \\
\hline
\end{tabular}


Table 5. Experimental Conditions for the EDM Process

\begin{tabular}{|c|c|}
\hline Deposition Condition & Detail \\
\hline Current $-\mathbf{I}_{\mathbf{p}}(\mathbf{A})$ & $1 \mathrm{~A}, 2 \mathrm{~A}, 3 \mathrm{~A}, 4 \mathrm{~A}$ \\
\hline Pulse on $-\mathbf{T}_{\mathbf{~ o n}}(\boldsymbol{\mu s})$ & $16 \mu \mathrm{s}, 32 \mu \mathrm{s}, 50 \mu \mathrm{s}, 200 \mu \mathrm{s}$ \\
\hline Pulse off $-\mathbf{T}_{\text {off }}(\boldsymbol{\mu s})$ & $50 \mu \mathrm{s}$ \\
\hline The dielectric fluid & Shell EDM Fluid 2 \\
\hline Polarity of Cu-electrode & Negative $(-)$ \\
\hline Current voltage $(\mathbf{V})$ & $80-120 \mathrm{~V}$ \\
\hline Powder concentration $(\mathbf{g} / \mathbf{l})$ & $20 ; 40 ; 60$ \\
\hline Dimension of workpiece & $\mathrm{D}=19 \mathrm{~mm} ; \mathrm{L}=50 \mathrm{~mm}$ \\
\hline
\end{tabular}

\section{Results and Discussion}

The conditions as shown in Table have been implemented. The following part deals with discussing the effects of varying the technological conditions on surface roughness.

\section{Effect of the Current (Ip) on the Surface Roughness (Ra)}

\section{The General Effect of PMEDM}

Figure 2 illustrates the different aspects related to the process phenomenon, including the metal particles in forming of discharge channels, the discharge process with metal particles during PMEDM and the surface roughness. Figures 3 to 10 present the surface roughness at various machining conditions.

It can be observed from Figures 3-6 that the surface roughness on the PMEDM process was less than that in conventional EDM for all pulse-on time.

The surface roughness changes follow the downward trend can be explained by the involvement of the metal powder particles during spark discharges. With the metal powder particles participating in the process spark discharges alter the electrical discharges on the following aspects.

As the powder is added, the spark gap distance between the electrode and workpiece increases $[2,10,16]$. The increase in gap spark distance when the discharge channel started to be formed has resulted from the arrangement of metal particles into the conductive beads. When the spark gap distance is increased, the energy of the spark discharges is weakening, thereby reducing the amount of machined material and thus led to the reduction in the depth and the width of the craters formed on the workpiece surface, resulted in the decrease of the surface roughness, as shown in Figure $2 \mathrm{a}$.

Also, when the metal particles involved in the process, the sparks are formed more evenly. In normal EDM, the sparks often occur at the nearest points between the cathode and anode. While in PMEDM, the metal particles help forming the discharge channel, resulting the possibility of sparking in various points, where metal particles formed a bridge due to the magnetic field. Due to the discharge process occurs at more points, the surface roughness was lower, as shown in Figures $2 \mathrm{~b}$ and $2 \mathrm{c}$. 


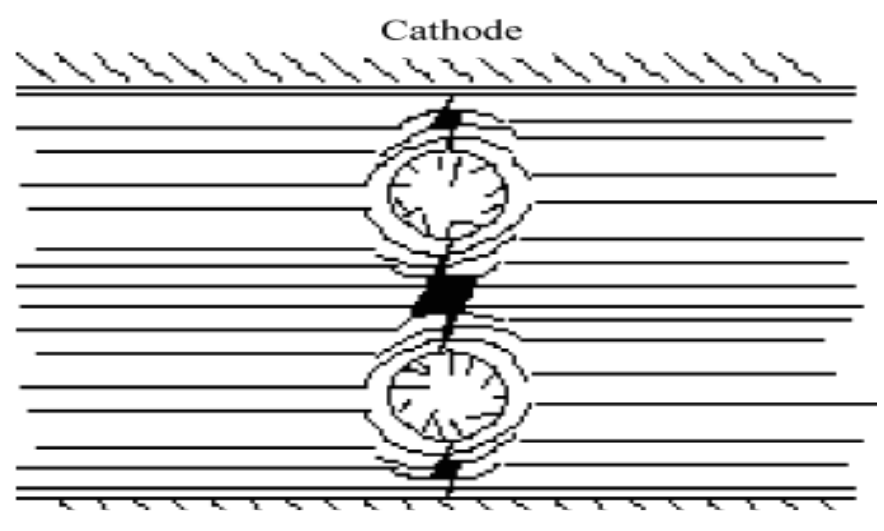

Figure 2a. Metal particles in forming of discharge channels [2]
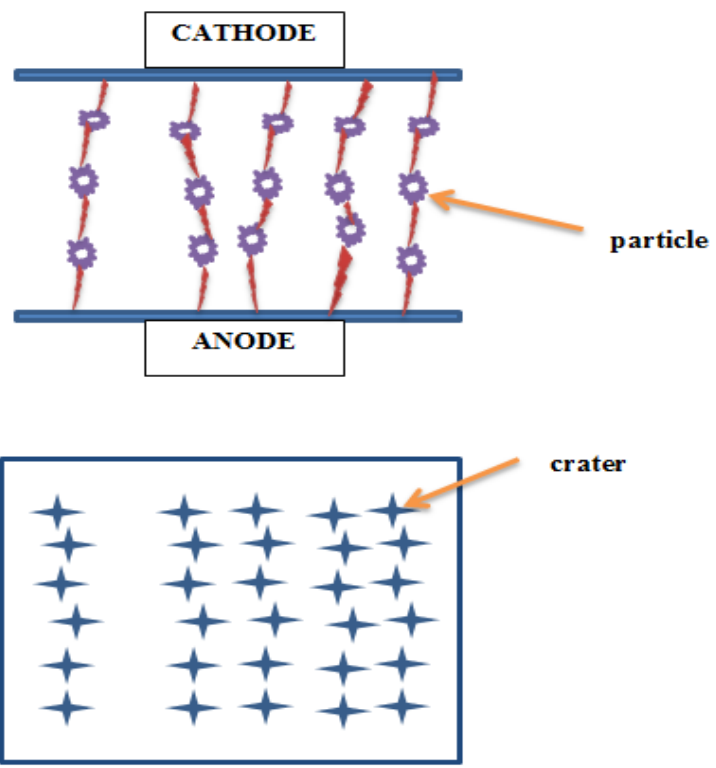

Figure $2 b$. Discharge process with metal particles during PMEDM
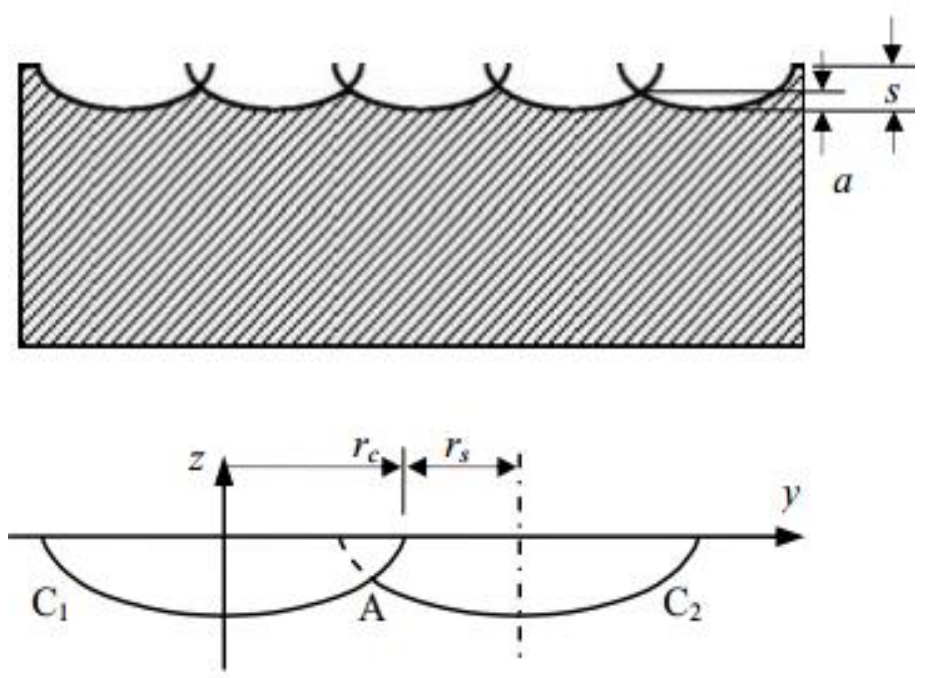

Figure 2c. Surface roughness [17] 
To calculate Ra, the author employed the equation proposed by Shabgard et al. [18]:

$$
R_{a}=\% P F E \frac{1}{4}\left[\frac{r_{c+} r_{s}}{r_{c}}\right]^{2} s
$$

where:

$\% \mathrm{PFE}=100 \times \mathrm{V}_{\mathrm{c}}(\mathrm{EXP}) / \mathrm{V}_{\mathrm{c}}(\mathrm{FEM})$

$\mathrm{V}_{\mathrm{c}}(\mathrm{FEM})=1 / 2\left(\pi \mathrm{S} \mathrm{r}_{\mathrm{c}}{ }^{2}\right)$

$\mathrm{V}_{\mathrm{c}}(\mathrm{EXP})=\left(\mathrm{M}_{1}-\mathrm{M}_{2}\right) /\left(\mathrm{N}_{\mathrm{np}} \times \rho\right)$

$\mathrm{r}_{\mathrm{s}}$ : Radius of plasma channel at the end of pulse on time $(\mu \mathrm{m})$

$\mathrm{r}_{\mathrm{c}:}$ Radius of the crater $(\mu \mathrm{m})$.

S: Depth of the crater $(\mu \mathrm{m})$.

$\mathrm{M}_{1}, \mathrm{M}_{2}$ : Workpiece weight before and after machining, respectively.

$\mathrm{N}_{\mathrm{np}}$ : Number of normal pulses.

$\rho$ : Density of the workpiece material $\left(\mathrm{kg} / \mathrm{m}^{3}\right)$.

\section{The Effect of the Process Parameters on the Surface Roughness Change}

It can be seen in Figure 3, consider $\mathrm{T}_{\text {on }}=16 \mu \mathrm{s}$, the concentration of $40 \mathrm{~g} / 1$ has the lowest surface roughness of $0.471 \mu \mathrm{m}$, equivalent to a reduction of $57.98 \%$ as compared to that of normal EDM. The concentration of $40 \mathrm{~g} / \mathrm{l}$ and $60 \mathrm{~g} / \mathrm{l}, \mathrm{T}_{\text {on }}=16 \mu$ s also has the biggest decrease in surface roughness as compared to others. In Figure 4, $\mathrm{T}_{\text {on }}=16 \mu \mathrm{s}$ with the concentration of $60 \mathrm{~g} / \mathrm{l}$ has the lowest surface roughness with the value of $0.727 \mu \mathrm{m}$, equivalent to a reduction of $44.84 \%$ as compared that at a concentration of $40 \mathrm{~g} / \mathrm{l}$.

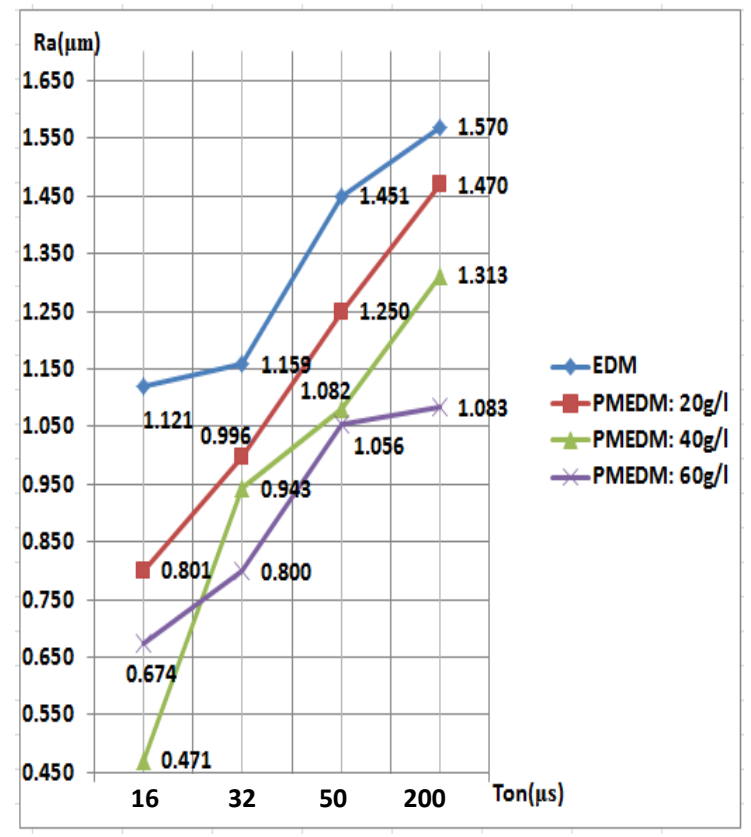

Figure 3. The surface roughness at $\mathrm{I}_{\mathrm{p}}=1 \mathrm{~A}$

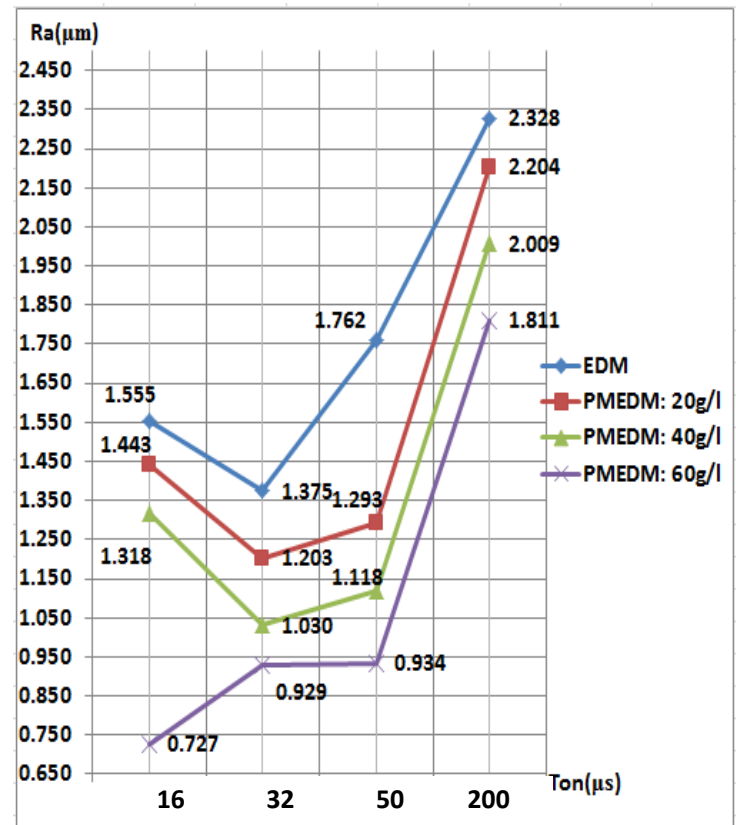

Figure 4. The surface roughness at $\mathrm{I}_{\mathrm{p}}=2 \mathrm{~A}$

The phenomenon can be explained as follows: Due to the appropriate combination between the spark discharge, the pulse-on and pulse-off time, the breaking pressure of gas bubble formed in the previous discharge period is small, causing the high concentration of the metal particles in the discharge channel formed for the next discharge period. While 
those particles are important in forming the bridge of the metal particles for spark discharge, such high concentration leads to an increase in the sparking distance, resulting in a more even density of spark discharge. In total, those are the main reasons for the improvement of the surface roughness of PMEDM as compared to EDM.

In the contrary, Figure 5 and 6 demonstrated the cases where PMEDM had no significant effects compared to EMD. In Figure 5, where $\mathrm{T}_{\text {on }}=16 \mu \mathrm{s}$, the concentration of $20 \mathrm{~g} / \mathrm{l}$ resulted in surface roughness of $1.613 \mu \mathrm{m}$, equivalent to a reduction of $2 \%$. Meanwhile, in Figure 6, where $\mathrm{T}_{\mathrm{on}}=32 \mu \mathrm{s}$, the concentration of $20 \mathrm{~g} / \mathrm{l}$ has the smallest surface roughness change as compared to that of EDM, only by $0.31 \%$. With the same $\mathrm{T}_{\text {on }}=$ $32 \mu \mathrm{s}$, the concentration of $40 \mathrm{~g} / \mathrm{l}$ has the least change in the surface roughness as compared to that of the concentration of $20 \mathrm{~g} / \mathrm{l}$, only by $1.3 \%$.

The cause of the phenomenon for those cases can be explained similarly to the above, where the inappropriate combination between the spark discharge, the pulse-on and pulse-off time, the breaking pressure of gas bubble formed in the previous discharge period is high, causing the low concentration of the metal particles in the discharge channel formed for the next discharge period. The resulting reduction in the sparking distance leads to a less even density of spark discharge and thus causes the non-significant improvement of the surface roughness of PMEDM as compared to EDM.

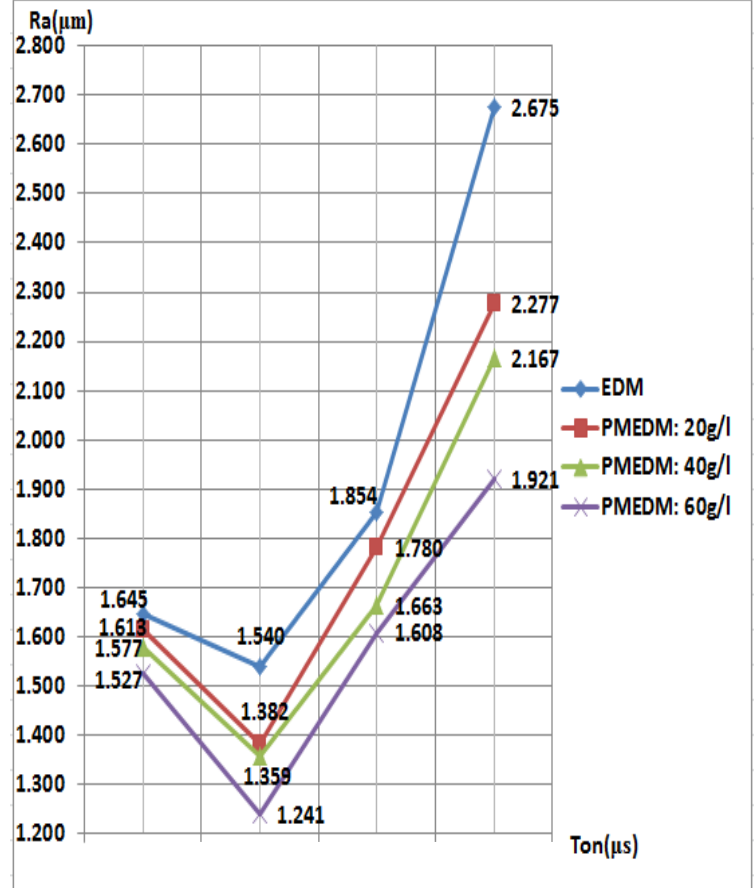

Figure 5. The surface roughness at $\mathrm{I}_{\mathrm{p}}=3 \mathrm{~A}$

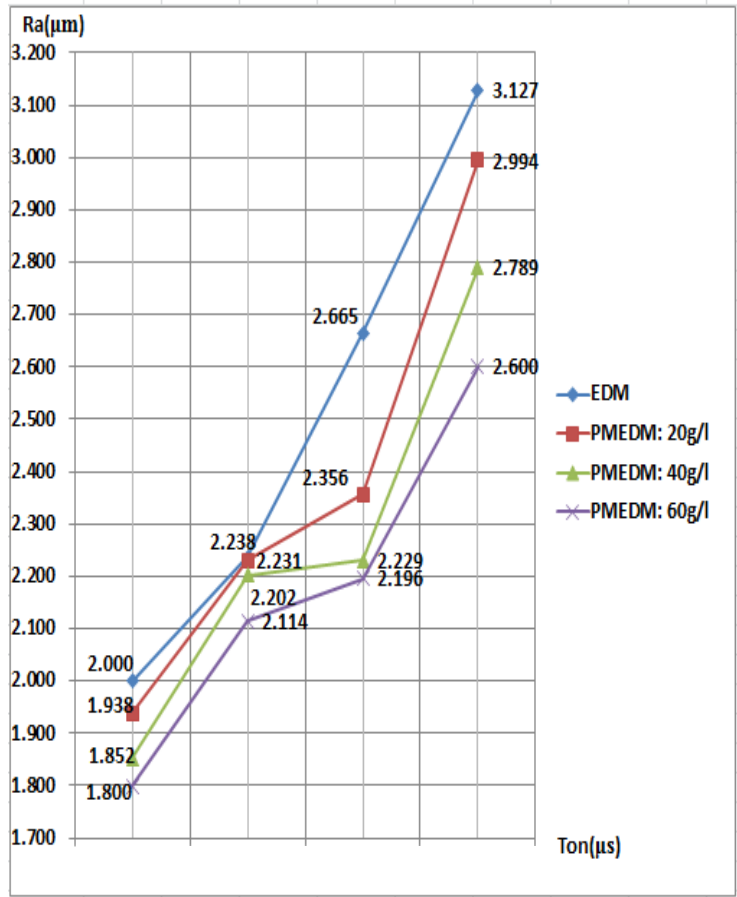

Figure 6 . The surface roughness at $\mathrm{I}_{\mathrm{p}}=4 \mathrm{~A}$

\section{The Effect of Pulse on Time on the Surface Roughness}

Figures $7-10$ illustrate the effect of pulse on time on the surface roughness at different experimental conditions. As seen from the figures, at the same powder concentrations, the surface roughness increases with $\mathrm{I}_{\mathrm{p}}=1 \mathrm{~A} ; \mathrm{I}_{\mathrm{p}}=2 \mathrm{~A} ; \mathrm{I}_{\mathrm{p}}=3 \mathrm{~A} ; \mathrm{I}_{\mathrm{p}}=4 \mathrm{~A}$ accordingly. This is consistent with the theory of EDM. Also, at the specific spark discharge time, the surface roughness decreases as the concentration of the alloy particles increases. The cause of this phenomenon was explained in section "The General Effect of PMEDM".

Consider two special cases in Figure 7 at the mode $T_{\text {on }}=16 \mu \mathrm{s}, \mathrm{I}_{\mathrm{p}}=1 \mathrm{~A}, 40 \mathrm{~g} / \mathrm{l}$ and in Figure 8 at the mode $\mathrm{T}_{\mathrm{on}}=50 \mu \mathrm{s}, \mathrm{I}_{\mathrm{p}}=2 \mathrm{~A}, 60 \mathrm{~g} / \mathrm{l}$, the surface roughness reaches unusual 
decreases, pointing out that those are the optimal mode for combining technological parameters which can help achieving the best surface roughness in the experiment window. The cause of this phenomenon is explained in section "The Effect of the Process Parameters on the Surface Roughness Change".

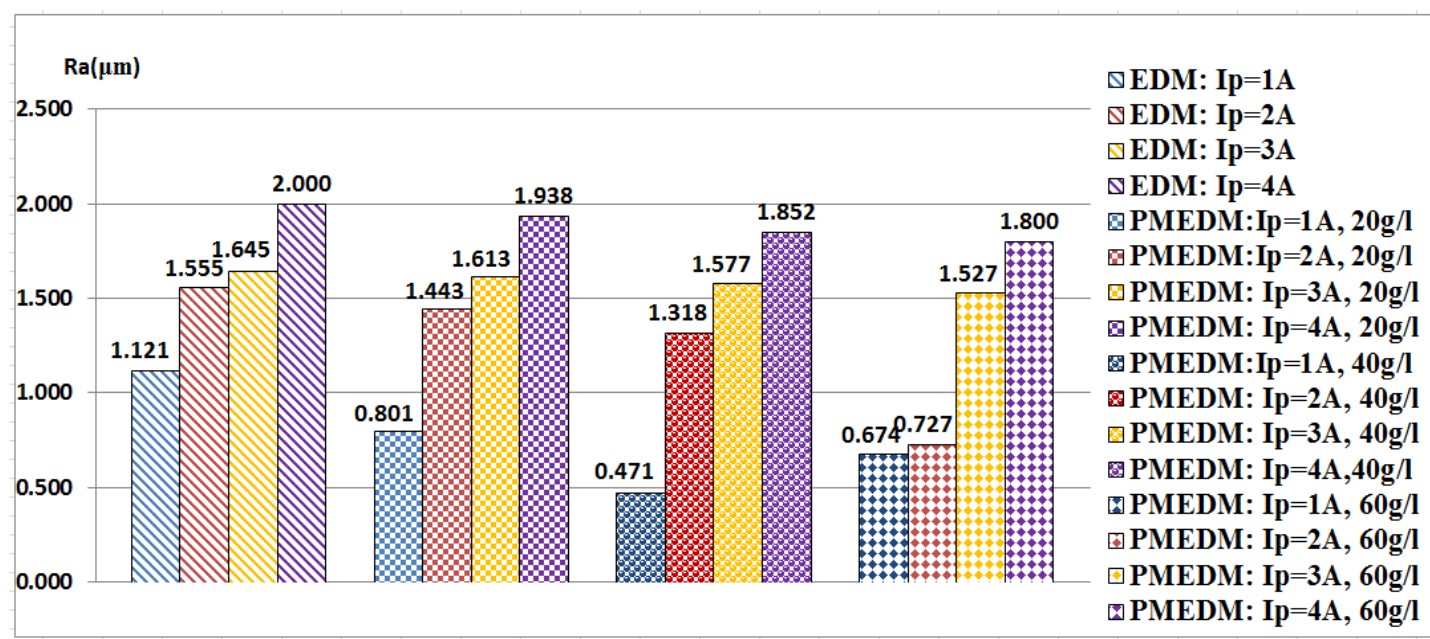

Figure 7. The surface roughness at $\mathrm{T}_{\mathrm{on}}=16 \mu \mathrm{s}$

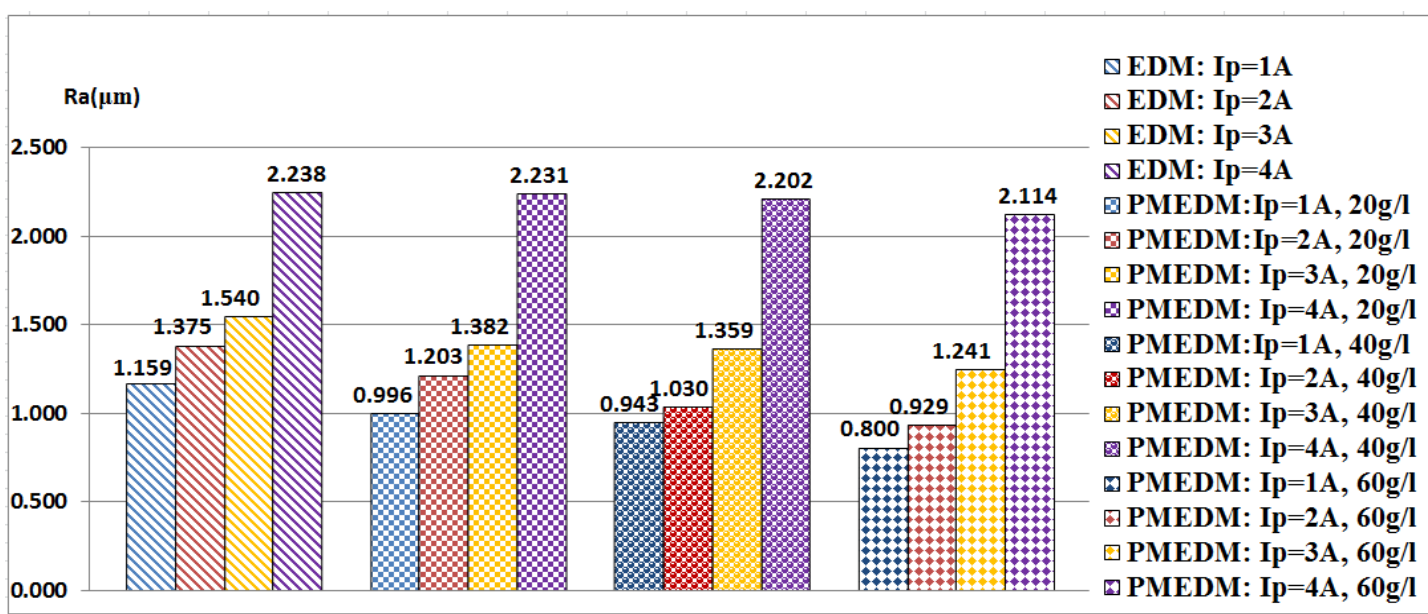

Figure 8. The surface roughness at $\mathrm{T}_{\text {on }}=32 \mu \mathrm{s}$

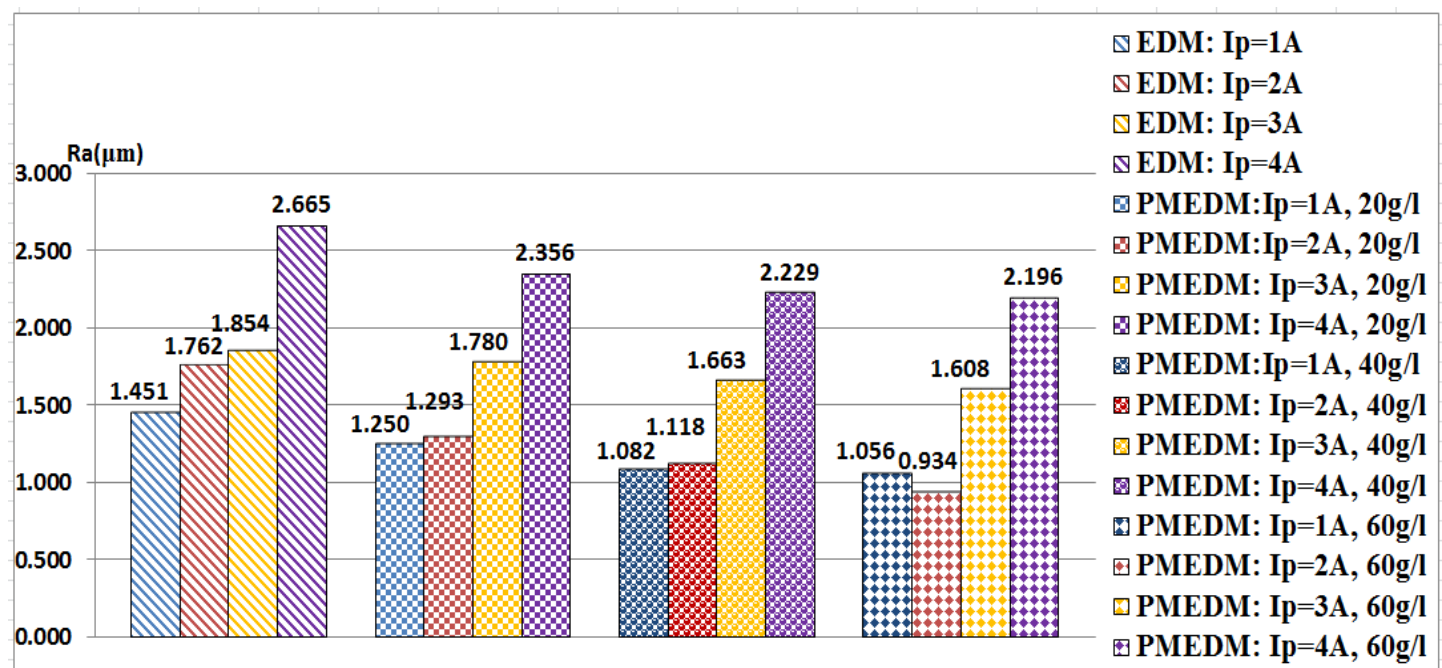

Figure 9. The surface roughness at $\mathrm{T}_{\mathrm{on}}=50 \mu \mathrm{s}$ 


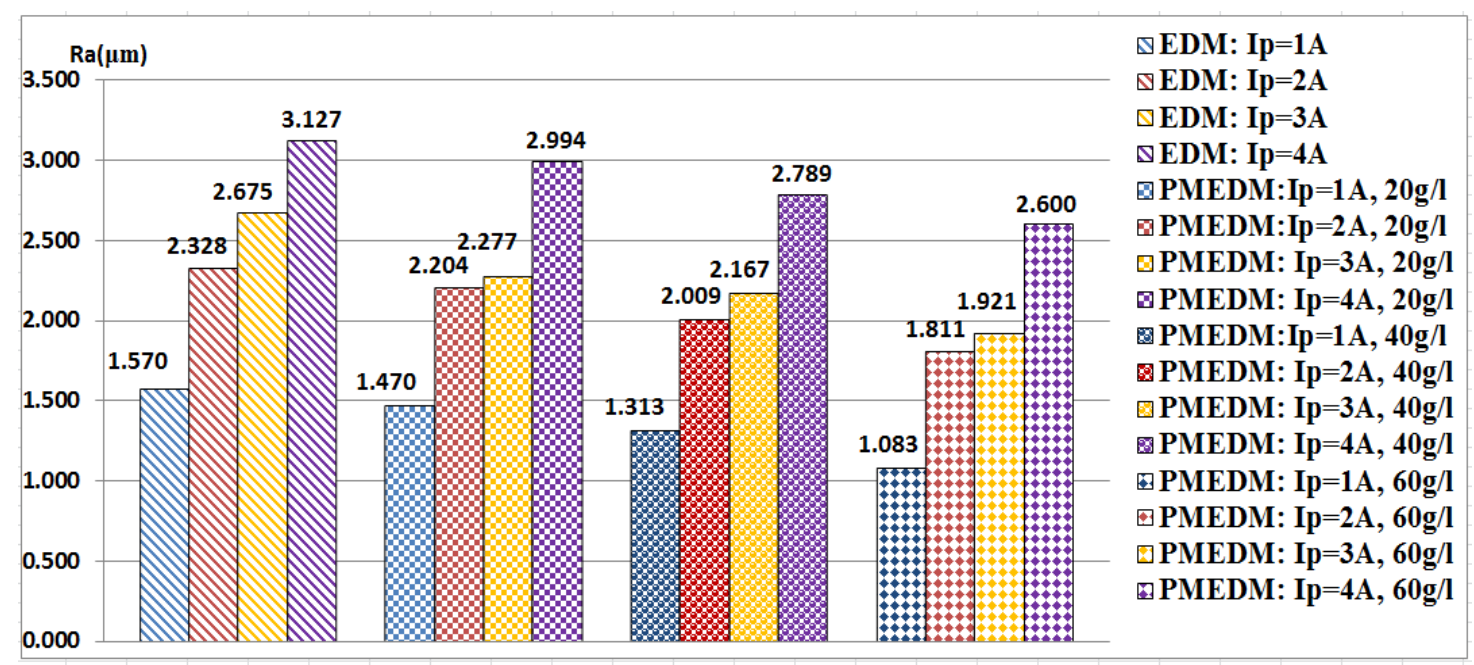

Figure 10. The surface roughness at $\mathrm{T}_{\mathrm{on}}=200 \mu \mathrm{s}$

\section{Conclusions}

Mixing tungsten carbide alloy particles into the dielectric fluid has resulted in an improvement of surface roughness of EDM. In general, tungsten carbide alloy in the dielectric fluid with various concentrations have made the surface roughness obtained in all electric modes better than those of the normal EDM. In this research, all powder concentrations produced improvements of surface roughness for all combinations of $\mathrm{I}_{\mathrm{p}}$ and $\mathrm{T}_{\mathrm{on}}$. However, at two modes where $\mathrm{T}_{\mathrm{on}}=16 \mu \mathrm{s}, \mathrm{I}_{\mathrm{p}}=1 \mathrm{~A}, 40 \mathrm{~g} / \mathrm{l}$ and $\mathrm{T}_{\mathrm{on}}=50 \mu \mathrm{s}, \mathrm{I}_{\mathrm{p}}=2 \mathrm{~A}, 60 \mathrm{~g} / \mathrm{l}$, the improvement of the surface roughness were optimal. Moreover, the biggest improvement of $57.98 \%$ as compared to normal EDM was reached for the parameter set where $\mathrm{I}_{\mathrm{p}}=1 \mathrm{~A}$; $\mathrm{T}_{\mathrm{on}}=16 \mu \mathrm{s}$; concentration of $40 \mathrm{~g} / \mathrm{l}$. Also, the parameter combination where $\mathrm{I}_{\mathrm{p}}=2 \mathrm{~A}$; $\mathrm{T}_{\mathrm{on}}=16 \mu \mathrm{s}$, the surface roughness of the concentration $60 \mathrm{~g} / \mathrm{l}$ reached the biggest change of $44.84 \%$ as compared to that of the concentration $40 \mathrm{~g} / \mathrm{l}$.

The current research has pointed out the possibility to improve the surface roughness of EMD surfaces by adding tungsten carbide powder into the dielectric fluid. It has also proved that by selecting appropriate combination of process parameters, the surface roughness can be significantly optimized.

\section{References}

[1] K. Furutani, A. Saneto, H. Takezawa, N. Mohri, and H. Miyake, "Accertation of titanium carbide by electrical discharge machining with powder suspended in working fluid," Journal of Precision Enineering., Vol. 25, No. 2, pp. 138-144, 2001.

[2] W.S. Zhao, Q.G. Meng, and Z.L. Wang, "The application of research on powder mixed EDM in rough machining," Journal of Materials Processing Technology, Vol. 129, No. 1-3, pp. 30-33, 2002.

[3] A. Erden, and S. Bilgin, "Role of impurities in electric discharge machining," In: Proceedings of the $21^{\text {st }}$ International Machine Tool Design and Research Conference, Macmillan, London, pp. 345-350, 1980.

[4] C.H. Wang, Y.C. Lin, B.H. Yan, and F.Y. Huang, "Effect of characteristics of added powder on electric discharge machining," Journal of Japan Institute of Light Metals, Vol. 42, No. 12, pp. 2597-2604, 2001.

[5] N. Mohri, N. Saito, M. Higashi, and N. Kinoshita, "A new process of finish machining on free surface by EDM methods," CIRP Annals, Vol. 40, No. 1, pp. 207-210, 1991. 
[6] N. Mohri, N. Saito, T. Takawashi, and K. Kobayashi, "Mirror-like finishing by EDM (Multi Divided Electrode Method)," In: Proceedings of the 25 th International Symposium on Machine Tool Design and Research, United Kingdom, pp. 329-336, 1985.

[7] N. Mohri, J. Tsukamoto, and M. Fujino, "Surface modification by EDM - an innovation in EDM with semi-conductive electrodes," In: Proceedings of Winter Annual Meet ASME, Vol. 34, pp. 21-30, 1988.

[8] K. Kobayashi, T. Magara, Y. Ozaki, and T. Yatomi, "The present and future developments of electrical discharge machining," In: Proceedings of the $2^{\text {nd }}$ International Conference on Dies and Mold Technology, Singapore, pp. 35-47, 1992.

[9] H. Narumiya, N. Mohri, N. Saito, H. Otake, Y. Tanekawa, T. Takawashi, and K. Kobayashi, "EDM by powder suspended working fluid," In: Proceedings of the $9^{\text {th }}$ ISEM, pp. 5-8, 1989.

[10] Y.S. Wong, L.C. Lim, I. Rahuman, and W.M. Tee, "Near-mirror-finish phenomenon in EDM using powder-mixed dielectric," Journal of Materials Processing Technology, Vol. 79, pp. 30-40, 1998.

[11] P. Pecas, and E.A. Henriques, "Influence of silicon powder mixed dielectric on conventional electrical discharge machining," International Journal of Machine Tools and Manufacturer, Vol. 43, No. 14, pp. 1465-1471, 2003.

[12] K.L. Wu, B.H. Yan, F.Y. Huang, and S.C. Chen, "Improvement of surface finish on SKD steel using electro-discharge machining with aluminum and surfactant added dielectric," International Journal of Machine Tools and Manufacture, Vol. 45, No. 10, pp. 1195-1201, 2005.

[13] Y. Tzeng, and F. Chen, "Investigation into some surface characteristics of electrical discharge machined SKD-11 using powder-suspension dielectric oil," Journal of Materials Processing Technology, Vol. 170, No. 1-2, pp. 385-391, 2005.

[14] Y.F. Chen, and Y.C. Lin, "Surface modifications of Al-Zn-Mg alloy using combined EDM with ultrasonic machining and addition of TiC particles into the dielectric," Journal of Materials Processing Technology, Vol. 209, No. 9, pp. 4343-4350, 2009.

[15] B. Jabbaripour, M.H. Sadeghi, M.R. Shabgard, and H. Faraji, "Investigating surface roughness, material removal rate and corrosion resistance in PMEDM of $\gamma$-TiAl intermetallic," Journal of Manufacturing Processes, Vol. 15, No.1, pp. 56-68, 2013.

[16] Y.F. Tzeng, and C.Y. Lee, "Effects of powder characteristics on electrodischarge machining efficiency," International Journal of Advanced Manufacturing Technology, Vol. 17, No. 8, pp. 586- 592, 2001.

[17] K. Salonitis, A. Stournaras, P. Stavropoulos, and G. Chryssolouris, "Thermal modeling of the material removal rate and surface roughness for die-sinking EDM," The International Journal of Advanced Manufacturing Technology, Vol. 40, No. 3-4, pp. 316-323, 2009.

[18] M. Shabgard, S. Nadimi Bavil, M. Seyedzavvar, and A. Najade-Brahimi, "Experimental investigation and 3D finite element prediction of the white layer thickness, heat affected zone, and surface roughness in EDM process," Journal of Mechanical Science and Technology, Vol. 25, No. 12, pp. 3173-3183, 2011. 